\title{
Durability of per-oral endoscopic myotomy beyond 6 years
}

\section{다 $(9)$}

\section{Authors}

Jad P. AbiMansour¹, Yervant Ichkhanian', Hitomi Minami², Pietro Familiari³, Rosario Landi³, Guido Costamagna ${ }^{3}$, Stefan Seewald ${ }^{4}$, Zachary M. Callahan ${ }^{5}$, Michael B. Ujiki ${ }^{5}$, Mathieu Pioche ${ }^{6}$, Thierry Ponchon ${ }^{6}$, Sabine Roman $^{6}$, Joo Young $\mathrm{Cho}^{7}$, In Kyung $\mathrm{Yoo}^{7}$, Megan Sippey ${ }^{8}$, Jeffrey M. Marks ${ }^{8}$, Nikolas Eleftheriadis ${ }^{9}$, Vivek Khumbari ${ }^{1}$, Olaya I. Brewer Gutierrez ${ }^{1}$, Mouen A. Khashab ${ }^{1}$

Institutions

1 Division of Gastroenterology and Hepatology Johns Hopkins Hospital, Baltimore, USA

2 Department of Gastroenterology and Hepatology Nagasaki University Hospital Nagasaki, Japan

3 Digestive Endoscopy Unit Fondazione Policlinico Universitario Agostino Gemelli IRCCS Rome, Italy

4 Center of Gastroenterology Hirslanden Private Clinic Group Zürich, Switzerland

5 Department of Surgery NorthShore University HealthSystem Evanston, USA

6 Gastroenterology Unit/Unit of Functional Disease and Digestive Physiology Edouard Herriot Hospital Lyon, France

7 Department of Gastroenterology, Cha Bundang Medical Center, Cha University College of Medicine, Seongnamsi, Korea

8 Case Western/University Hospitals Cleveland Medical Center, Cleveland, USA

9 Metropolitan Hospital, Athens, Greece

submitted 3.8.2020

accepted after revision 26.4.2021

Bibliography

Endosc Int Open 2021; 09: E1595-E1601

DOI 10.1055/a-1553-9846

ISSN 2364-3722

(C) 2021. The Author(s).

This is an open access article published by Thieme under the terms of the Creative Commons Attribution-NonDerivative-NonCommercial License, permitting copying and reproduction so long as the original work is given appropriate credit. Contents may not be used for commercial purposes, or adapted, remixed, transformed or built upon. (https://creativecommons.org/licenses/by-nc-nd/4.0/)

Georg Thieme Verlag KG, Rüdigerstraße 14,

70469 Stuttgart, Germany
Corresponding author

Mouen A. Khashab, MD, Division of Gastroenterology and Hepatology, Johns Hopkins Hospital, 1800 Orleans Street,

Suite 7125G, Baltimore, MD 21287, USA

Fax: +1-443-683-8335

mkhasha1@jhmi.edu

\section{ABSTRACT}

Background and study aims The aim of this study was to assess long-term clinical outcomes beyond 6 years in patients who underwent per-oral endoscopic myotomy (POEM) for the treatment of achalasia.

Patients and methods Patients with achalasia who underwent POEM between 2010 and 2012 and had follow-up of at least 6 years were retrospectively identified at eight tertiary care centers. The primary outcome evaluated was clinical success defined by an Eckardt symptom score (ESS) $\leq 3$ for the duration of the follow-up period. The clinical success cohort was compared to failure (ESS $>3$ at any time during follow-up) in order to identify characteristics associated with symptom relapse. The incidence of patient-reported gastroesophageal reflux (GER) was also evaluated.

Results Seventy-three patients with 6-year follow-up data were identified. Sustained clinical remission was noted in $89 \%(65 / 73)$ at 6-years. Mean ESS decreased from 7.1 \pm 2.3 pre-procedure to $1.1 \pm 1.1$ at 6 years $(P<0.001)$. Symptomatic reflux was reported by 27 of 72 patients $(37.5 \%)$. Type I achalasia (OR 10.8, P=0.04) was found to be associated with clinical failure on logistic regression analysis.

Conclusions In patients with achalasia, POEM provides high initial clinical success with excellent long-term outcomes. There are high rates of patient-reported gastroesophageal reflux post-procedure which persist at longterm follow-up. 


\section{Introduction}

Achalasia is a rare motility disorder of the esophagus associated with the loss of myenteric neurons that control peristalsis and relaxation of the lower esophageal sphincter (LES). Esophageal dysfunction leads to progressive symptoms of solid and liquid dysphagia, regurgitation, and atypical chest pain which significantly impact quality of life [1]. There is no known cure for achalasia but the mainstay of treatment is disruption of the LES using botulinum toxin injection, pneumatic balloon dilation, or myotomy.

Per-oral endoscopic myotomy (POEM), a type of natural orifice transluminal endoscopic surgery, performed without any cutaneous incisions, has emerged as a novel, safe, and effective treatment of achalasia [2,3]. It has quickly become the goldstandard in experienced centers, and studies have shown a robust clinical response in greater than $90 \%$ of patients within the first year [4-11]. However, the natural history of achalasia is one of an incurable and progressive disease. Response to therapy tends to diminish over time regardless of treatment modality, making the assessment of long-term outcomes critically important $[12,13]$.

Studies suggest treatment response to POEM is maintained in the first two to three years with remission rates between $88-90 \%$, but true long-term follow-up is sparse and limited to small cohorts and single-center case series [14-16]. There are currently no studies examining outcomes of POEM beyond 5 years. We performed this international, multicenter cohort study to assess the long-term ( $>6$ years) effectiveness of POEM and identify clinical features that may be associated with treatment failure over time.

\section{Patients and methods}

This retrospective cohort study was approved by the Institutional Review Board for Human Research at The Johns Hopkins Hospital and subsequently by each center enrolled in the study. We retrospectively identified consecutive, adult patients $(>18$ years old) who underwent POEM for the treatment of achalasia between 2010 and 2012 at eight tertiary care centers (2 United States, 4 Europe, 2 Asia). Records were identified from electronic health records and procedural databases. Those with telephone or in-person follow-up after at least 6 years were included in the study. Efforts were made at each center to obtain follow-up information by telephone when not available in the medical record, but ultimately patients without documented follow-up at 6 years were excluded. Patients who underwent POEM for alternative indications, including diffuse esophageal spasm, esophagogastric junction outflow obstruction, and jackhammer esophagus, were also excluded. The majority of patients in this cohort were included in previously published studies on shorter-term outcomes, incidence of gastroesophageal reflux disease, and adverse events (AEs) after POEM however clinical outcomes have never been reported beyond 4 years [6, 17-21].

While POEM technique has been well-described in the current literature, specific technical aspects of the procedure as well as post-operative management were determined by the standard of practice at each individual center. Generally, the procedure was performed with a cap-fitted endoscopic approach with patients under general anesthesia and on positivepressure ventilation. Patients were kept nil per os overnight and underwent esophagram with water-soluble contrast on postoperative day one to exclude esophageal leak prior to diet advancement and discharge.

Chart review was performed by each center and data extracted into a central database. In addition to baseline demographic and clinical information, procedural data collected included myotomy orientation, myotomy thickness, esophageal and gastric myotomy length, and procedure-related AEs. AEs were graded as mild, moderate, or severe based on the American Society for Gastrointestinal Endoscopy (ASGE) lexicon for endoscopic AEs [22]. All data analysis was conducted at the coordinating center (The Johns Hopkins Hospital).

Clinical response was evaluated at 6 years using Eckardt symptom score (ESS). The ESS is a validated self-assessment tool that is the gold-standard for assessing symptom severity with fair reliability and validity $[23,24]$. It includes patient-reported grading of dysphagia, chest pain, regurgitation and weight loss. Scores at 6, 12, 24, 36 and 48 months were reported when available. The primary outcome was clinical success defined as ESS $\leq 3$ for the duration of follow-up with treatment failure representing a score $>3$ at any time during the follow-up period. In patients with missing data for specified time points, the last observation was carried forward. A score $\leq 3$ has been shown to be suggestive of active achalasia, and this definition is consistent with that used in prior studies, including multiple randomized controlled trials [24-26]. Additional outcomes of interest included clinical characteristics associated with treatment failure and prevalence of gastroesophageal reflux as defined by patient-reported symptoms, use of proton pump inhibitors (PPIs), and presence of esophagitis on esophagogastroduodenoscopy.

Patients were divided into clinical success (ESS $\leq 3)$ and clinical failure $(E S S>3)$ cohorts. Baseline characteristics included patient demographics, prior therapies, esophagus shape, LES relaxation pressure, and pre-procedure ESS. Diagnosis was categorized based on the Chicago Classification of esophageal motility disorders [27]. Procedural data was collected as described above. Symptomatic reflux and PPI use were assessed at last follow-up. Esophageal acid exposure/pH measurement, endoscopy findings, and manometry were reported when available.

Quantitative variables were described with mean value and standard deviation. Categorical values were described with frequencies (\%). We assessed for clinically relevant differences among patients who experienced treatment failure. Univariate analysis was performed using standard using paired $t$-test for quantitative data and, for categorical data, chi-square tests or Fisher's exact tests when event frequency was less than five. Missing data that was not available from retrospective chart review were excluded in comparisons. $P \leq 0.05$ was considered statistically significant. Statistical analysis was performed using SPSS software (SPSS version 25, Chicago, Ilinois, United States). 


\section{Results}

A total of 76 patients from eight centers were initially identified during the study period. The number of patients contributed by each center was $32,31,11$, nine, three, three, two, and one. Four patients $(21 \%)$ were excluded alternative indication of diffuse esophageal spasm (2/19), and lack of documented ESS (2/ 19) ( $\triangleright$ Fig. 1). Therefore, 73 patients (63.0\% female, mean age 49.7 years) with a median follow-up time of 79.5 months (IQR 73.9-82.6) were analyzed. Baseline demographic and clinical information are reported in $>$ Table 1 . Preoperative diagnoses were achalasia type I (16 patients, $21.9 \%$ ), type 2 (15 patients, $20.6 \%$ ), type 3 (4 patients, $5.5 \%$ ), and achalasia of unspecified type (38 patients, $52.1 \%$ ). Six patients $(8.2 \%)$ had a sigmoidshaped esophagus. Twenty-three patients (31.5\%) had undergone prior treatment, three of which underwent multiple interventions. These treatments included 21 pneumatic dilation (28.8\%), four botulinum toxin injection (5.5\%), and two Heller myotomy $(2.7 \%)$. The mean baseline ESS was $7.1 \pm 2.3$. All procedures resulted in successful completion of the myotomy. Anterior orientation was used in sixty-three (86.3\%) of cases. The majority of myotomies were partial-thickness (52 [69.9\%]) compared to 22 (30.1\%) full-thickness. Mean esophageal and gastric myotomy length was $9.5 \pm 3.2 \mathrm{~cm}$ and $2.7 \pm 1.6 \mathrm{~cm}$, respectively. A total of six AEs occurred (8.2\%), including one cardiac arrhythmia (severe), one delayed bleed (moderate), one esophageal leak (severe), and three mucosotomies (all mild).

At 6 years, clinical success was noted in $89 \%(65 / 73)$ with a $95 \%$ confidence interval ranging from 82 to $96 \%$. Not all patients had follow-up data available at the pre-specified interval follow-up times. The average number of follow-up visits per patient was $5.5 \pm 1.2$ visits. Three patients had two follow-up visits

\section{7 identified during study period}

4 excluded:

$\rightarrow \quad 2$ alternative indication (2 DES)

- 2 no ESS recorded

73 met inclusion criteria and were reviewed

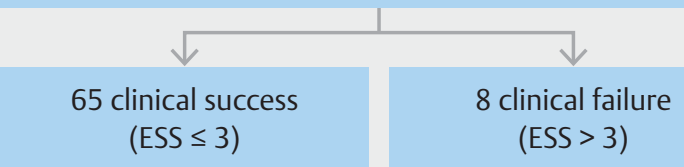

- Fig. 1 Flow diagram of study design and patient identification. DES, diffuse esophageal spasm; ESS, Eckardt symptom score.

documented due to unavailability of records. ESS was carried forward from the most recent follow-up to calculate interval success rates of $96 \%(70 / 73), 94 \%(69 / 73), 93 \%(68 / 73)$ and $92 \%(67 / 73)$ at $6,12,24$, and 48 months, respectively.

In subgroup analysis of patients who achieved remission by 6 months, the clinical success rate at 6 years increased to $95.5 \%$. Three of eight patients failed within the first 6 months and average ESS was higher in the treatment failure cohort 6 months post-procedure (3.2 vs $0.6, P=0.007$ ). This persisted for most of the follow-up duration ( $\triangleright$ Fig. 2). Achalasia subtype was also slightly different between the two groups. Patients who experienced treatment failure were more likely to have a diagnosis of type I achalasia (75\% vs. $15.4 \%, P=0.005$ ) but otherwise showed similar demographic, procedural, and clinical characteristics to those with clinical success ( $\vee$ Table 2 ). Clinical char-

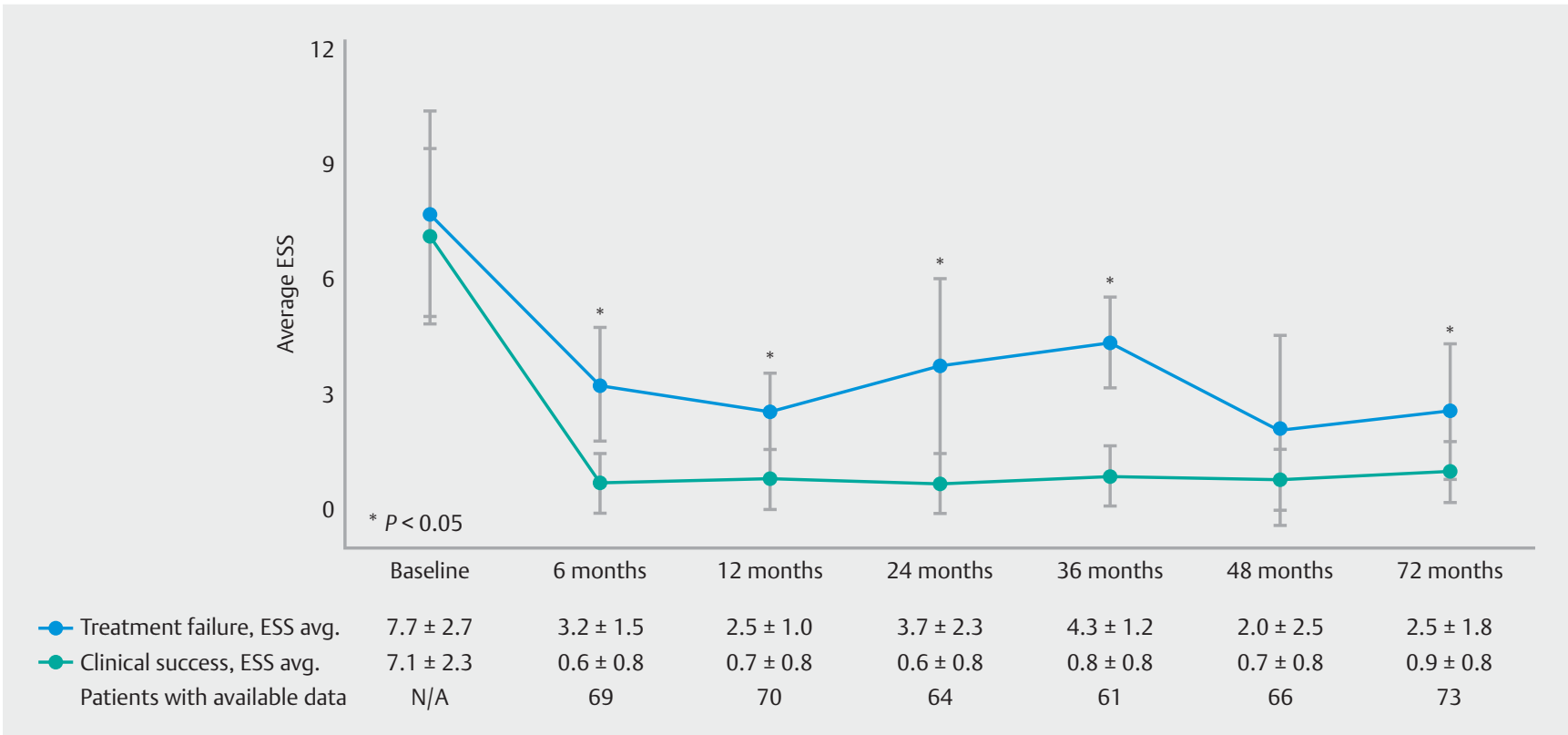

- Fig. 2 Average Eckardt symptom score (ESS) in patients with clinical failure (black line) and clinical success (gray line) with standard deviation as error bars. Significant differences are seen as early as 6 months post-procedure. 
- Table 1 Baseline and peri-procedural characteristics.

\begin{tabular}{|c|c|c|}
\hline & $\begin{array}{l}\text { Patients with } \\
\text { available data } \\
\mathrm{N}=73 \text { unless } \\
\text { specified }\end{array}$ & $\begin{array}{l}\text { Overall } \\
\text { (n 73) }\end{array}$ \\
\hline Age, years (mean $\pm S D$ ) & & $49.7 \pm 17.4$ \\
\hline $\mathrm{BMI}, \mathrm{kg} / \mathrm{m}^{2}($ mean $\pm \mathrm{SD})$ & 37 & $26.5 \pm 12.4$ \\
\hline Female, no. (\%) & & $46(63.0)$ \\
\hline \multicolumn{3}{|l|}{ Disease Classification } \\
\hline - Type 1 & & $16(21.9)$ \\
\hline - Type 2 & & $15(20.6)$ \\
\hline - Type 3 & & $4(5.5)$ \\
\hline Unspecified & & $38(52.1)$ \\
\hline Any prior therapy, no. (\%) & & $23(31.5)$ \\
\hline Pneumatic dilation, no. (\%) & & $21(28.8)$ \\
\hline Botox, no. (\%) & & $4(5.5)$ \\
\hline Heller myotomy, no. (\%) & & $2(2.7)$ \\
\hline $\begin{array}{l}\text { Sigmoidal esophageal shape, } \\
\text { no. (\%) }\end{array}$ & 72 & $6(8.2)$ \\
\hline HRM IRP, mm Hg (mean \pm SD) & 25 & $32.5 \pm 14.2$ \\
\hline $\begin{array}{l}\text { HRM resting pressure, } \mathrm{mmHg} \\
(\text { mean } \pm \mathrm{SD})\end{array}$ & 45 & $41.2 \pm 20.0$ \\
\hline $\begin{array}{l}\text { Pre-poem Eckhart score, } \\
\text { mean } \pm \text { SD }\end{array}$ & 71 & $7.1 \pm 2.3$ \\
\hline $\begin{array}{l}\text { Anterior orientation of myot- } \\
\text { omy, no. (\%) }\end{array}$ & 67 & $63(86.3)$ \\
\hline $\begin{array}{l}\text { Full-thickness LES myotomy, no. } \\
\text { (\%) }\end{array}$ & & $22(30.1)$ \\
\hline $\begin{array}{l}\text { Esophageal myotomy length, } \\
\mathrm{cm}(\text { mean } \pm \text { SD) }\end{array}$ & & $9.5 \pm 3.2$ \\
\hline $\begin{array}{l}\text { Gastric myotomy length, } \mathrm{cm} \\
(\text { mean } \pm \text { SD) }\end{array}$ & 71 & $2.5 \pm 0.8$ \\
\hline $\begin{array}{l}\text { Patients with adverse events, } \\
\text { no. (\%) }\end{array}$ & & $6(8.2)$ \\
\hline $\begin{array}{l}\text { Follow-up time, months, median } \\
\text { (IQR) }\end{array}$ & 50 & $\begin{array}{l}79.5 \\
(73.9-82.6)\end{array}$ \\
\hline $\begin{array}{l}\text { HRM, high-resolution manometry; IRF } \\
\text { lower esophageal sphincter; IQR, inte } \\
\text { hibitor. }\end{array}$ & $\begin{array}{l}\text { tegrated relaxatic } \\
\text { artile range; PPI, }\end{array}$ & $\begin{array}{l}\text { ressure; LES, } \\
\text { on pump in- }\end{array}$ \\
\hline
\end{tabular}

acteristics of patients who experienced clinical failure (8/73 (11\%)) are shown in $>$ Table 3.

Symptomatic reflux was reported by 23 patients $(31.5 \%)$ at 6-year follow-up with a similar number (23 [31.5\%]) taking daily PPIs. Six patients (8.2\%) were using PPIs intermittently and 44 (60.3\%) were not on any PPI therapy at last follow-up. Endoscopy information was available in 60 cases; however, the majority were performed within 3 years of the original procedure (average $1.7 \pm 1.4$ years post-procedure). Esophagitis was pres-
- Table 2 Comparison of baseline and peri-procedural characteristics of patients who experienced clinical response versus clinical failure.

\begin{tabular}{|c|c|c|}
\hline & $\begin{array}{l}\text { Clinical } \\
\text { success } \\
(E S S \leq 3) \\
n=65\end{array}$ & $\begin{array}{l}\text { Clinical } \\
\text { failure } \\
(E S S>3 \text { ) } \\
n=8\end{array}$ \\
\hline Age, years (mean $\pm S D$ ) & $50.6 \pm 18.0$ & $42.4 \pm 10.1$ \\
\hline $\mathrm{BMI}, \mathrm{kg} / \mathrm{m} 2($ mean $\pm \mathrm{SD})$ & $26.3 \pm 12.6$ & $28.3 \pm 11.6$ \\
\hline Female, no. (\%) & $41(63.1)$ & $5(62.5)$ \\
\hline \multicolumn{3}{|l|}{ Disease Classification } \\
\hline Type 1 & $10(15.4)^{1}$ & $6(75.0)^{1}$ \\
\hline Type 2 & $14(21.5)$ & $1(12.5)$ \\
\hline Type 3 & $4(6.2)$ & $0(0.0)$ \\
\hline Unspecified & 37 (56.9) & $1(12.5)$ \\
\hline Any prior therapy, no. (\%) & $22(33.9)$ & $1(12.5)$ \\
\hline Pneumatic dilation, no. (\%) & $20(30.8)$ & $1(12.5)$ \\
\hline Botox, no. (\%) & $4(6.2)$ & $0(0.0)$ \\
\hline Heller myotomy, no.(\%) & $2(3.1)$ & $0(0.0)$ \\
\hline Sigmoidal esophageal shape, no. (\%) & $6(9.2)$ & $0(0.0)$ \\
\hline \multicolumn{3}{|l|}{ Pre-POEM HRM, mean \pm SD } \\
\hline IRP, $\mathrm{mmHg}$ & $32.4 \pm 15.1$ & $33.1 \pm 9.2$ \\
\hline Resting pressure, $\mathrm{mmHg}$ & $41.2 \pm 20.1$ & $41.4 \pm 21.1$ \\
\hline Pre-POEM ESS, mean \pm SD & $7.1 \pm 2.3$ & $7.7 \pm 2.7$ \\
\hline $\begin{array}{l}\text { Anterior orientation of myotomy, } \\
\text { no. }(\%)\end{array}$ & $57(93.4)$ & $6(100.0)$ \\
\hline Full thickness LES myotomy, no. (\%) & $18(27.7)$ & $4(50.0)$ \\
\hline $\begin{array}{l}\text { Esophageal myotomy length, } \mathrm{cm} \\
(\text { mean } \pm \text { SD) }\end{array}$ & $9.5 \pm 3.3$ & $8.9 \pm 2.1$ \\
\hline $\begin{array}{l}\text { Gastric myotomy length, } \mathrm{cm} \\
(\text { mean } \pm \text { SD) }\end{array}$ & $2.5 \pm 0.8$ & $2.7 \pm 0.8$ \\
\hline Patients with adverse events, no. (\%) & $16(24.6)$ & $0(0.0)$ \\
\hline $\begin{array}{l}\text { Follow up time, months, median } \\
\text { (IQR) }\end{array}$ & $\begin{array}{l}76.9 \\
(73.9-82.2)\end{array}$ & $\begin{array}{l}81.6 \\
(74.7-89.1)\end{array}$ \\
\hline
\end{tabular}

Pre-POEM HRM, $\mathrm{mmHg}($ mean $\pm \mathrm{SD})$

\begin{tabular}{|l|l|l|}
\hline IRP, $\mathrm{mmHg}$ & $11.4 \pm 7.8$ & $16.7 \pm 14.2$ \\
\hline Resting pressure, $\mathrm{mmHg}$ & $18.1 \pm 9.1$ & $14.1 \pm 7.5$ \\
\hline
\end{tabular}

ESS, Eckardt Symptom Score; HRM, high-resolution manometry; IRP, integrated relaxation pressure; LES, lower esophageal sphincter; IQR, interquartile range; PPI, proton pump inhibitor; SD, standard deviation. $1 P \leq 0.05$.

ent in 20 cases ( $28.3 \%$ ) with 13 grade A, 3 grade B, one grade D, and three unknown grading as defined by the Los Angeles Classification System. 
- Table 3 Demographic and clinical information of patients who experienced clinical failure.

\begin{tabular}{|c|c|c|c|c|c|c|c|c|c|}
\hline & $\begin{array}{l}\text { Age } \\
\text { (y) }\end{array}$ & Gender & $\begin{array}{l}\text { Achalasia } \\
\text { Subtype }\end{array}$ & $\begin{array}{l}\text { Eckardt } \\
\text { Score } \\
\text { (pre, post) }\end{array}$ & $\begin{array}{l}\text { HRM IRP, } \\
\text { mm Hg } \\
\text { (pre, post) }\end{array}$ & $\begin{array}{l}\text { Response } \\
\text { at } 6 \\
\text { months? }\end{array}$ & $\begin{array}{l}\text { Time of } \\
\text { failure }\end{array}$ & Further treatment & $\begin{array}{l}\text { Symptomatic } \\
\text { improvement }\end{array}$ \\
\hline 1 & 33 & Female & Type I & 5,4 & $30.0,36.0$ & - & 6 months & $\begin{array}{l}\text { Conservative man- } \\
\text { agement }\end{array}$ & + \\
\hline 2 & 50 & Male & Type I & 6,5 & $23.4,6.6$ & - & 6 months & $\begin{array}{l}\text { Conservative man- } \\
\text { agement }\end{array}$ & - \\
\hline 3 & 61 & Male & Type I & 6,4 & $\mathrm{Na}$ & - & 6 months & $\begin{array}{l}\text { Conservative man- } \\
\text { agement }\end{array}$ & + \\
\hline 4 & 54 & Female & Type II & 7,1 & $33.5,11.7$ & + & 12 months & Pneumatic dilation & + \\
\hline 5 & 25 & Female & Type II & 11,3 & $45.4,18.7$ & + & 24 months & Pneumatic dilation & + \\
\hline 6 & 42 & Female & Type I & 11,2 & $43.5,5.3$ & + & 36 months & Pneumatic dilation & + \\
\hline 7 & 52 & Male & Type I & $\mathrm{Na}, 4$ & $\mathrm{Na}$ & $\mathrm{Na}$ & 6 years & $\begin{array}{l}\text { Conservative man- } \\
\text { agement }\end{array}$ & NA \\
\hline 8 & 37 & Female & Unspecified & $\mathrm{Na}, 6$ & $\mathrm{Na}$ & $\mathrm{Na}$ & 6 years & Pneumatic dilation & + \\
\hline
\end{tabular}

- Table4 Gastroesophageal reflux after POEM in patients with clinical response versus clinical failure.

\begin{tabular}{|l|l|l|l|}
\hline & $\begin{array}{l}\text { Overall } \\
\mathbf{n}=\mathbf{7 3}\end{array}$ & $\begin{array}{l}\text { Clinical success } \\
\text { (ESS } \mathbf{3}) \\
\mathbf{n = 6 5}\end{array}$ & $\begin{array}{l}\text { Clinical failure } \\
\text { (ESS } \mathbf{3}) \\
\mathbf{n = 8}\end{array}$ \\
\hline Symptomatic reflux at last follow-up, no. (\%) & $27 / 72(37.5)$ & $25 / 64(39.1)$ & $2 / 8(25.0)$ \\
\hline PPI use at last follow up, no. (\%) & $29(39.7)$ & $27(41.5)$ & $2(25.0)$ \\
\hline Daily & $23(31.5)$ & $22(33.9)$ & $1(12.5)$ \\
\hline Occasionally & $6(8.2)$ & $5(7.7)$ & $1(12.5)$ \\
\hline None & $44(60.3)$ & $38(58.5)$ & $6(75.0)$ \\
\hline Esophagitis on EGD, no. (\%) & $20 / 65(30.8)$ & $17 / 57(29.8)$ & $3 / 3(100.0)$ \\
\hline EGD, esophagogastroduodenoscopy; ESS, Eckardt Symptom Score; PPI, proton pump inhibitor. & \\
\hline
\end{tabular}

\section{Discussion}

This is the first study examining POEM outcomes at 6 years and we have shown a robust and durable clinical response in this patient cohort. A clinical success rate of $89 \%$ is consistent with existing 3- to 5-year data ranging from $83 \%$ to $90 \%[3,25,28-30]$. While 6-year data have not been previously published, a handful of groups have reported retrospective 5-year data from individual centers. In North America, Stravapolous et al. reported a 5 -year success rate of $90 \%$ in 49 patients (abstract) and Teitelbaum et al. $83 \%$ in 29 patients [28, 30]. Li et al. reported an $87 \%$ success rate in 47 patients with follow-up ranging from 4 to 5 years from a single center in Asia [29].

In our cohort, significant differences in average ESS emerged as early as 6 months post-procedure and over $95 \%$ of patients with clinical success at 6 months remained in remission for the duration of follow-up. As a point of comparison, laparoscopic Heller myotomy remission rates after 5 years vary from $57 \%$ to $88 \%$ but studies directly comparing long-term outcomes with POEM are not available, given the novelty of the procedure, variability in study design, and limited randomized data [31-33]. Our results suggest that long-term effectiveness is comparable to conventional therapy based on historic data, but further studies are certainly needed.

Type I achalasia was the sole clinical factor associated with clinical failure (OR 10.8, $P<0.001)$. However, the high number of patients with unspecified achalasia subtype in this cohort makes inferring the clinical significance of this finding difficult and limits generalizability. In larger series, POEM has been shown to be effective across all three manometric subtypes [34]. Type III achalasia has been least responsive to traditional therapy, but POEM is thought to be particularly advantageous as it allows for customization and lengthening of the myotomy $[35,36]$. All four patients with type III achalasia in this cohort were treated successfully. In these patients, average esophageal and gastric myotomy lengths were $2.3 \pm 1.0$ and $7.0 \pm 3.6$ $\mathrm{cm}$, respectively. Further assessment of the impact of achalasia 
subtype on clinical outcome was limited by a high number of unclassified diagnoses (38 patients [52.1\%]) attributed to delayed adoption of high-resolution manometry as the first procedures were performed in early 2012.

Other than achalasia subtype, failure and success groups showed similar clinical and procedural characteristics. Outcome was notably independent of any prior treatment (OR $3.58,95 \% \mathrm{Cl} 0.41-30.97)$, which is consistent with prior studies suggesting POEM is effective in patients who have failed previous endoscopic and surgical interventions. Studies report remission rates of $75 \%$ to $100 \%$ for patients with prior myotomy and $87 \%$ to $100 \%$ with prior PD but are limited by follow-up length of less than 1 year [7,37-40]. Two of two patients (100\%) with prior surgical myotomy and 20 of 21 (95\%) with prior PD had sustained response at 6 years, supporting the role of POEM as salvage therapy in previously treating patients.

Pathologic gastroesophageal reflux (GER) remains a critical disadvantage of POEM in this study with over one-third of patients reporting symptomatic reflux (37.5\%) and a similar number on daily PPI therapy (31.5\%). Esophagitis was noted in $28 \%$ of individuals who underwent endoscopy ( $>$ Table 4). Evaluation with endoscopy and $\mathrm{pH}$ monitoring was typically performed in the early postoperative period, but objective, long-term data were not available for the vast majority of patients. POEM is typically performed at tertiary centers where routine follow-up may involve extra travel and cost for patients, but the lack of objective reflux data highlights significant variability in postprocedure surveillance at each center. In a recent randomized trial comparing POEM to laparoscopic Heller myotomy with rigorous post-procedure monitoring, $30 \%$ of POEM patients had abnormal esophageal $\mathrm{pH}$ exposure at 24 months [26]. While objective $\mathrm{pH}$ exposure data were not available in our cohort, the symptomatic reflux rates and PPI use at 6 years are consistent with this. Determining the optimal approach to iatrogenic GER remains an area of ongoing investigation.

The limitations of this study include its retrospective design and reliance on ESS as the primary outcome. While ESS remains the gold standard in current literature and achalasia trials, a patient with a score of 3 (defined as clinical success) may still be experience dysphagia on a daily basis. Using the score as the sole indicator of clinical success also makes it difficult to determine if failure was due to true clinical failure or pseudoachalasia secondary to reflux. In future studies, consideration should be given to additional, objective evaluation of disease activity using other data like HRM, bolus retention time, and quality of life measurements. It is also important to note that this cohort represents some of the earliest patients to undergo POEM in these centers, which resulted in significant variation in procedural volume and half of the centers contributing fewer than 10 cases. These limited samples and selection bias (including self-selection by patients and operator case selection) may limit generalizability to current practice. Data that were not available during retrospective chart review also were excluded from comparisons, which limits external and internal validity.

\section{Conclusions}

In conclusion, this international, multicenter study reports the longest follow-up of a POEM cohort to date and shows enduring symptomatic relief. Sustained clinical response was noted in $89 \%$ of patients regardless of prior treatment and, if in clinical remission at 6 months, the probability of response at 6 years was even higher. This information contributes to the limited body of literature regarding true long-term data as POEM adoption increases around the world. GER remains a common occurrence that continues to impact patients many years after their procedure, and further investigation is required to establish standardized long-term surveillance and management.

\section{Competing interests}

Dr. N. Thosani is a consultant for Boston Scientific, Medtronic, Endogastric Solutions, and Pentax of America; a speaker for Abbvie, and receives royalties from UpToDate. Dr. M.A. Khashab is a consultant for Boston Scientific, Medtronic and Olympus. Dr. Alessandro Repici MD -Boston consulting fee, speaker fee, research grant. Fujifilm advisory board speaker fee. ERBE advisory board consulting fee. EndoKey advisory board. EndoStart advisory board. Medtronic research grant, consulting fee, advisory board. Dr. Sachin Wani is a Consultant for Boston Scientific, Medtronic, Cernostics and Interpace. Supported by the University of Colorado Department of Medicine Outstanding Early Scholars Program. All remaining authors declare they have nothing to disclose.

References

[1] Boeckxstaens GE, Zaninotto G, Richter JE. Achalasia. Lancet 2014; 383: 83-93

[2] Pasricha PJ, Hawari R, Ahmed I et al. Submucosal endoscopic esophageal myotomy: a novel experimental approach for the treatment of achalasia. Endoscopy 2007; 39: 761-764

[3] Inoue $\mathrm{H}$, Minami H, Kobayashi Y et al. Per-oral endoscopic myotomy (POEM) for esophageal achalasia. Endoscopy 2010; 42: 265-271

[4] Parsa N, Khashab MA. POEM in the treatment of esophageal disorders. Curr Treat Options Gastroenterol 2018; 16: 27-40

[5] Evensen $\mathrm{H}$, Kristensen $\mathrm{V}$, Larssen L et al. Outcome of per-oral endoscopic myotomy (POEM) in treatment-naive patients. A systematic review. Scand J Gastroenterol 2019: doi:10.1080/00365521.2018. 1549271

[6] Familiari P, Gigante G, Marchese M et al. Per-oral Endoscopic myotomy for esophageal achalasia: outcomes of the first 100 patients with short-term follow-up. Ann Surg 2016; 263: 82-87

[7] Ling T, Guo H, Zou X. Effect of per-oral endoscopic myotomy in achalasia patients with failure of prior pneumatic dilation: A prospective case-control study. J Gastroenterol Hepatol 2014; 29: 1609-1613

[8] Ramchandani M, Reddy DN, Darisetty S et al. Per-oral endoscopic myotomy for achalasia cardia: Treatment analysis and follow up of over 200 consecutive patients at a single center. Dig Endosc 2016; 28: $19-26$

[9] Sharata AM, Dunst CM, Pescarus R et al. Per-oral endoscopic myotomy (POEM) for esophageal primary motility disorders: analysis of 100 consecutive patients. J Gastrointest Surg 2015; 19: 161-170

[10] Von Renteln D, Fuchs K, Fockens P et al. Per-oral endoscopic myotomy for the treatment of achalasia: an international prospective multicenter study. Gastroenterology 2013; 145: 309-311.e3 
[11] von Renteln D, Inoue H, Minami H et al. Per-oral endoscopic myotomy for the treatment of achalasia: a prospective single center study. Am J Gastroenterol 2012; 107: 411-417

[12] Ellis FG. The natural history of achalasia of the cardia abridged. Proc $R$ Soc Med 1960; 53: 663-666

[13] Salvador R, Voltarel G, Savarino E et al. The natural history of achalasia: Evidence of a continuum - "The evolutive pattern theory". Dig Liver Dis 2018; 50: 342-347

[14] Guo H, Yang H, Zhang X et al. Long-term outcomes of per-oral endoscopic myotomy for patients with achalasia: a retrospective singlecenter study. Dis Esophagus 2017; 30: 1-6

[15] Hungness ES, Sternbach JM, Teitelbaum EN et al. Per-oral endoscopic myotomy (POEM) after the learning curve: durable long-term results with a low complication rate. Ann Surg 2016; 264: 508-517

[16] Martinek J, Svecova H, Vackova Z et al. Per-oral endoscopic myotomy (POEM): mid-term efficacy and safety. Surg Endosc 2018; 32: 12931302

[17] Kumbhari V, Familiari P, Bjerregaard NC et al. Gastroesophageal reflux after per-oral endoscopic myotomy: a multicenter case-control study. Endoscopy 2017; 49: 634-642

[18] Arevalo G, Sippey M, Martin-Del-Campo LA et al. Post-POEM reflux: who's at risk? Surg Endosc 2019: doi:10.1007/s00464-019-07086-1

[19] Haito-Chavez Y, Inoue H, Beard KW et al. Comprehensive Analysis of adverse events associated with per oral endoscopic myotomy in 1826 patients: an international multicenter study. Am J Gastroenterol 2017; 112: 1267-1276

[20] Chen Y-I, Inoue H, Ujiki M et al. An international multicenter study evaluating the clinical efficacy and safety of per-oral endoscopic myotomy in octogenarians. Gastrointest Endosc 2018; 87: 956-961

[21] Brewer Gutierrez OI, Moran R, Familiari P et al. Long-term outcomes of per-oral endoscopic myotomy in achalasia patients with a minimum follow-up of 4 years: a multicenter study. Gastrointest Endosc 2018; 87: AB564-AB565

[22] Cotton PB, Eisen GM, Aabakken L et al. A lexicon for endoscopic adverse events: report of an ASGE workshop. Gastrointest Endosc 2010; 71: 446-454

[23] Eckardt VF, Aignherr C, Bernhard G. Predictors of outcome in patients with achalasia treated by pneumatic dilation. Gastroenterology 1992; 103: 1732-1738

[24] Taft TH, Carlson DA, Triggs J et al. Evaluating the reliability and construct validity of the Eckardt symptom score as a measure of achalasia severity. Neurogastroenterol Motil 2018; 30: e13287

[25] Peng L, Tian S, Du C et al. Outcome of per-oral endoscopic myotomy (POEM) for treating achalasia compared with laparoscopic Heller myotomy. Surg Laparosc Endosc Percutan Tech 2017; 27: 60-64

[26] Werner YB, Hakanson B, Martinek J et al. Endoscopic or surgical myotomy in patients with idiopathic achalasia. N Engl J Med 2019; 381: $2219-2229$
[27] Kahrilas PJ, Bredenoord A], Fox M et al. The Chicago Classification of esophageal motility disorders, v3.0. Neurogastroenterol Motil Off J Eur Gastrointest Motil Soc 2015; 27: 160-174

[28] Teitelbaum EN, Dunst CM, Reavis KM et al. Clinical outcomes five years after POEM for treatment of primary esophageal motility disorders. Surg Endosc 2018; 32: 421-427

[29] Li Q-L, Wu Q-N, Zhang X-C et al. Outcomes of per-oral endoscopic myotomy for treatment of esophageal achalasia with a median followup of 49 months. Gastrointest Endosc 2018; 87: 1405-1412.e3

[30] Stavropoulos SN, Modayil RJ, Zhang X et al. Tu1146 per oral endoscopic myotomy (POEM) For achalasia: long term outcomes from a large prospective single-center US series. Gastrointest Endosc 2018; 87: AB540-AB541

[31] Ujiki MB, Yetasook AK, Zapf M et al. Per-oral endoscopic myotomy: A short-term comparison with the standard laparoscopic approach. Surgery 2013; 154: 893-900

[32] Bhayani NH, Kurian AA, Dunst CM et al. A comparative study on comprehensive, objective outcomes of laparoscopic Heller myotomy with per-oral endoscopic myotomy (POEM) for achalasia. Ann Surg 2014; 259: 1098-1103

[33] Teitelbaum EN, Rajeswaran S, Zhang R et al. Per-oral esophageal myotomy (POEM) and laparoscopic Heller myotomy produce a similar short-term anatomic and functional effect. Surgery 2013; 154: 885891; discussion 891-892

[34] Inoue $\mathrm{H}$, Sato $\mathrm{H}$, Ikeda $\mathrm{H}$ et al. Per-oral endoscopic myotomy: a series of 500 patients. J Am Coll Surg 2015; 221: 256-264

[35] Kim WH, Cho JY, Ko WJ et al. Comparison of the outcomes of per-oral endoscopic myotomy for achalasia according to manometric subtype. Gut Liver 2017; 11: 642-647

[36] Kumbhari V, Tieu AH, Onimaru M et al. Per-oral endoscopic myotomy (POEM) vs laparoscopic Heller myotomy (LHM) for the treatment of Type III achalasia in 75 patients: a multicenter comparative study. Endosc Int Open 2015; 3: E195-E201

[37] Tyberg A, Seewald S, Sharaiha RZ et al. A multicenter international registry of redo per-oral endoscopic myotomy (POEM) after failed POEM. Gastrointest Endosc 2017; 85: 1208-1211

[38] Li Q-L, Yao L-Q, Xu X-Y et al. Repeat per-oral endoscopic myotomy: a salvage option for persistent/recurrent symptoms. Endoscopy 2016; 48: $134-140$

[39] Ngamruengphong S, Inoue H, Ujiki MB et al. Efficacy and safety of per-oral endoscopic myotomy for treatment of achalasia after failed Heller myotomy. Clin Gastroenterol Hepatol Off Clin Pract J Am Gastroenterol Assoc 2017; 15: 1531-1537.e3

[40] Fumagalli U, Rosati R, De Pascale S et al. Repeated Surgical or endoscopic myotomy for recurrent dysphagia in patients after previous myotomy for achalasia. J Gastrointest Surg 2016; 20: 494-499 